\title{
Concepçōes de professores sobre a sexualidade de alunos e a sua formação em educação inclusiva $^{1}$
}

\author{
Ana Claudia Bortolozzi Maia* \\ Teresa Vilaça**
}

\section{Resumo}

A educação sexual no contexto da escola é um processo importante que deve ser realizado pelos professores para todos os alunos. O objetivo desta revisão de literatura foi analisar as concepçôes de professores sobre a sexualidade de alunos com deficiência intelectual. Os artigos foram localizados em bases de dados na área da Educação e, a partir de critérios de exclusão, elegeram-se 83 artigos para análise de conteúdo. Encontraram-se as seguintes categorias: "educação sexual" ( $n=22)$; "aspectos da sexualidade de pessoas com deficiências" ( $n=28)$; "questôes teóricas" ( $n=6)$; e "profissionais e familiares" $(\mathrm{n}=27)$. Esta última categoria foi desmembrada em: "concepções de professores" ( $n=7)$; "concepçôes de profissionais da saúde/cuidadores" ( $n=6)$, "concepçôes e expectativas de adultos que convivem com pessoas com deficiência" ( $\mathrm{n}=9$ ); e "implementação de programas de educação sexual" ( $n=5)$. Nos sete artigos sobre as concepçôes dos professores, estes reconhecem que os alunos com deficiência intelectual são seres sexuais e têm manifestações sexuais na escola; compreendem essa sexualidade como "exagerada" e consideram que eles não entendem as informações recebidas. Os professores são favoráveis à educação sexual na escola, mas, há aqueles que não consideram que esse seja o seu papel e outros que poderiam contribuir, apesar de necessitarem de preparação pessoal, formação continuada, materiais específicos e apoio da família. Estes resultados contribuem para o planejamento de cursos de formação de professores, visando o desenvolvimento de atitudes positivas: segurança no conhecimento científico, postura acolhedora, disponibilidade, respeito e tolerância, dentre outras, favorecendo a implementação da educação sexual na escola inclusiva.

Palavras-chave: Concepçóes de professores; Educação sexual; Deficiência intelectual; Formaçáo de professores.

\footnotetext{
* Professora doutora da Universidade Estadual Paulista Júlio de Mesquita Filho, Bauru, São Paulo, Brasil.
}

** Doutora em Educação pela Universidade do Minho, Braga, Portugal. 


\section{Teachers' conceptions regarding the sexuality of students and their formation in inclusive education}

\section{Abstract}

School-based sexual education is an important process that must be performed by teachers for all students. The objective of this literature review study was to analyse the teachers' conceptions regarding the sexuality of students with intellectual disability. The papers were localized in databases in the area of Education and, based on exclusion criteria, 83 papers were selected for content analysis. The following categories were found: "sexual education" ( $n=22)$; "aspects of sexuality of individuals with disabilities" ( $n=28)$; "theoretical issues" ( $n=6)$; and "professionals and relatives" ( $n=27)$. The last category was dismembered in the following subcategories: "conceptions of teachers" ( $\mathrm{n}=7)$; "conceptions and expectations of adults living with individuals with disabilities" ( $n=9)$; "conceptions of health professionals/caregivers" ( $n=6)$; and "implementation of sexual education programs" $(n=5)$. In the seven papers on teacher conceptions, teachers recognize that students with intellectual disabilities are sexual beings and have sexual manifestations in the school; they understand their sexuality as "exaggerated" and consider that they do not understand the information received. Teachers are favourable to the sexual education at school. However, there are those who do not consider that as their role and others could contribute to sexuality education. They need personal preparation, continuing formation, specific materials and family support. These results are useful to the planning of teacher training courses, aiming the development of positive attitudes, namely: confidence in scientific knowledge, welcoming posture, availability, respect and tolerance, among others, favouring the implementation of sexual education in inclusive school.

Keywords: Conceptions of teachers. Sexual education. Intellectual disability. Teacher training.

\section{Introdução}

Parece certo que pesquisadores, educadores, familiares e profissionais que trabalham e convivem com pessoas com diferentes deficiências compartilham da ideia de que todas elas são "sujeitos de direitos". Dentre esses direitos, defender os direitos sexuais e reprodutivos, esbarra numa questão complexa: a sexualidade e o tabu que ainda existe sobre as práticas sexuais, desejos, necessidades, conjugalidade, paternidade e maternidade, etc.

O exercício desse direito depende, sobretudo, de condiçóes objetivas, tais como o enfrentamento de barreiras arquitetônicas, de comunicação e atitudinais e o acesso a uma educação sexual que garanta esclarecimentos, informaçôes, orientaçôes etc, ou seja, é preciso que toda a sociedade esteja disposta a colaborar para que isso aconteça e, no caso da educação sexual, é do professor que se espera essa responsabilidade. 
No entanto, falar de sexualidade no contexto escolar para muitos professores ainda é uma tarefa complexa, mesmo quando este conteúdo é inserido no currículo oficial acadêmico. Disciplinas que esbarram em valores morais, hábitos culturais, dogmas religiosos etc, devem se valer da disposição de professores para assumirem uma relação de ensino e aprendizagem que não reproduza as suas próprias convicçóes pessoais. Então, quem deve ser esse professor? Que atributos ou crenças deve ter? De que formação ele necessita? Que atitudes são desejáveis? Como auxiliá-los a desenvolverem essas atitudes?

Enfim, são essas questôes que propomos pensar neste artigo, que tem por objetivo descrever as concepçóes de professores diante da sexualidade de alunos com deficiência, a partir de uma revisão de literatura, para propor uma capacitação de professores que os auxilie a desenvolver atitudes favoráveis à educaçáo sexual de seus alunos.

\section{Referêncial Teórico}

A sexualidade é compreendida como um conceito amplo que abrange as práticas sexuais, sentimentos afetivos, identidades etc., que tem representaçóes sociais e históricas. É um conceito abrangente que extrapola a genitalidade na medida em que se refere aos sentimentos, emoçóes, afetividade e também às relaçóes sexuais, e todas essas expressóes têm sentidos diversos dependendo da cultura e do momento histórico em que elas ocorrem (ANDERSON, 2000; MAIA, 2010; VILAÇA, 2017).

O fato é que a sexualidade é uma condição humana e qualquer pessoa, independentemente de haver uma deficiência ou não, é uma pessoa sexuada que tem um corpo erótico, geralmente desenvolvido psicossexualmente como as demais pessoas, e que tem o direito de exercer essa sexualidade da melhor maneira possível, assim como os demais direitos humanos (FRANÇA-RIBEIRO, 2012; GESSER; NUERNBERG, 2014; MAIA, 2016; SÁNCHEZ, 2008).

As pessoas com deficiência têm menos acesso às informaçóes sobre sexualidade e têm poucas oportunidades de receberem uma educaçáo sexual que lhes possibilite compreender melhor as mudanças do seu corpo, os seus sentimentos e os comportamentos sexuais e suas consequências (ANDERSON, 2000; HATTON; TECTOR, 2010; LUMLEY; SCOTTI, 2001; MAIA 2006; 2012; 2016; PEREIRA; VILAÇA, 2012; VIEIRA; COELHO, 2014; VILAÇA, 2012) e, quando recebem, muitas vezes, é uma educação que não lhes garante o aprendizado necessário.

Muitos jovens com deficiência, por falta de educação, acabam por expressar a sua sexualidade de modo inadequado: comportamentos exibicionistas, toques inapropriados, auto manipulação pública etc e se tornam mais vulneráveis às situaçóes de violência, ao abuso sexual e ao contágio de doenças sexualmente transmissíveis (LUMLEY; SCOTTI, 2001; MAIA, 2016). Pesquisadores têm reiterado que receber educação sexual é um direito que as pessoas com deficiência têm e que pode diminuir esses comportamentos considerados inadequados e reduzir as suas vulnerabilidades (FRANÇA-RIBEIRO, 2012; GESSER; NUERNBERG, 2014; MAIA, 2016; SANCHEZ, 2008; SCHWIER; HINGSBURGER, 2007). 
Apesar de a sexualidade ser parte integral de todo o ser humano, lidar com essa questão, especialmente no sentido de incluí-la em currículos acadêmicos de educação sexual para alunos com deficiências, ainda é uma dificuldade para muitos professores. Segundo Black (2005), as crenças pessoais sobre sexualidade têm impacto na pratica profissional de educadores, que devem oferecer a educaçáo sexual para adolescentes, considerando as características que expressam a sua sexualidade: relacionamentos com outras pessoas, desenvolvimento físico e sexual, curiosidade sexual, etc. No caso de adolescentes com deficiência, essa vivência pode significar para eles um período ainda mais confuso e a educação sexual, portanto, é ainda mais necessária.

A educação sexual na escola é uma proposta em muitos países, seja por recomendação, ou legislação, mas ainda é comum que muitos professores evitem realizá-la, quer por não a entenderem como necessária, quer por não se sentirem preparados a fazê-lo (COUWENHOVEN, 2007; HEIGHWAY; WEBSTER, 2008; KAUFMAN; SILVERBERG; ODETTE, 2003; KOLLER, 2000; MAIA, 2006; MAIA et al. 2015; MAIA; ARANHA, 2005; VILAÇA, 2016; WALKER-HIRSCH, 2007).

Estudos evidenciam que os professores não têm domínio teórico para assumirem a educação sexual de modo geral e, quando é destinada aos alunos com deficiência, a falta de formaçáo é somada às dificuldades em estabelecer objetivos, eleger os melhores procedimentos e escolher os materiais mais adequados à educação sexual de alunos quando esses têm uma deficiência (ALBUQUERQUE; ALMEIDA, 2010; CHIRAWU et al. 2014; MAIA et al. 2015; VILAÇA, 2016; WILKENFELD; BALLAN, 2011).

Além disso, Anderson (2000), Maia e Ribeiro (2010) e Sanchez (2008) acreditam que as crenças sobre a sexualidade de pessoas com deficiências desencorajam também os professores no oferecimento da educaçáo sexual. Por exemplo, ao acreditarem que as pessoas com deficiência intelectual são hiperssexuadas, temem falar sobre isso para não aumentar os comportamentos sexuais incontroláveis. Por outro lado, acreditar que elas seriam assexuadas, ingênuas e desprovidas de desejo também leva professores e familiares a achar que não seria recomendável tal abordagem (BANIM; GUY; TASKER, 1999; MAIA; RIBEIRO, 2010; SCHAAFSMA et al. 2014).

No entanto, é o não oferecimento da educação sexual que aumenta a vulnerabilidade a que são expostas, porque podem demonstrar certa ingenuidade, mas o seu erotismo e o seu corpo são compatíveis com o seu desenvolvimento cronológico (ANDERSON, 2000; COUWENHOVEN, 2007; KAUFMAN ET AL, 2003; MAIA, 2006; 2012; MORALES E BATISTA, 2010; SANCHEZ, 2008; SCHWIER \& HINGBURGER, 2007).

Neste sentido, o oferecimento desta necessária educação sexual para alunos com deficiência depende, em grande medida, da disposição pessoal e da formação do professor. Os estudos de Albuquerque e Almeida (2010) e Maia e Aranha (2005) mostram que muitos professores assumem dificuldades para lidar com as manifestaçôes sexuais desses alunos e agem ignorando ou reprimindo. Essas atitudes dos professores geralmente ocorrem porque eles desconhecem o desenvolvimento da se- 
xualidade, os processos de educação sexual e também porque se baseiam em crenças que justificam esses comportamentos como causa da deficiência (EAST; ORCHARD, 2013; MAIA et al., 2015; MAIA; ARANHA, 2005; MAIA; RIBEIRO, 2010).

Se pensarmos no professor como o responsável pela educação sexual na escola inclusiva, é imprescindível que esse professor seja alvo de investigação e de investimento. Levantar junto a professores suas dificuldades, expectativas, crenças e atitudes é importante para o estabelecimento de metas e para a elaboração de propostas que enriqueçam e complementem a formação de que eles necessitam.

Diante dessas consideraçôes, realizamos esta pesquisa que teve por objetivo descrever as concepçóes de professores diante da sexualidade de alunos com deficiência, a partir de uma revisão de literatura, para propor uma capacitação que os auxilie a desenvolver atitudes favoráveis para realizarem educação sexual na escola.

\section{Método}

Trata-se de um estudo de revisão sistemática da literatura. Os procedimentos de coleta e de análise de dados ocorreram da forma que a seguir se explica. Elegeramse algumas bases de dados relevantes na área da Educação: Emerald, Science Direct, Springer, Taylor \& Francis e Scielo, por meio do portal de acesso da Biblioteca da Universidade do Minho (UMinho, Braga, Portugal). Em seguida, iniciou-se uma busca por artigos utilizando duas palavras-chaves: "sexuality education" and "disability". Deste levantamento inicial, obtivemos 891 referências e destas foram excluídas aquelas que não se referiam aos "artigos completos", aquelas que apresentavam livros e/ou resenhas e as que se limitavam a entrevistas/editoriais, resultando em 315 artigos. Para restringir ainda mais a amostra, foram excluídos os artigos que náo eram escritos em língua inglesa e que eram repetidos, resultando em um número final de 83 artigos. Em todas essas etapas contamos com a participação de dois juízes independentes que colaboraram nessa seleção.

A análise de dados consistiu na organização dos artigos por categorias temáticas, tal como propóe Bardin (2011), nos seguintes passos: (a) leitura e pré-análise (leitura flutuante, escolha dos documentos, seleção do que será analisado e elaboração de indicadores, por meio de recortes de textos nos documentos analisados); (b) agrupamento e exploração do material, elaborando categorias temáticas mutuamente exclusivas.

\section{Resultados}

\section{Análise geral dos artigos por categorias temáticas}

Os 83 artigos foram lidos, na íntegra, e organizados em quatro categorias temáticas gerais, quais sejam: "Educação Sexual", "Profissionais e Familiares", "Aspectos da sexualidade de pessoas com deficiências" e "Questóes teóricas", descritas na Tabela 1, com a temática que as constituem e seus correspondentes números de artigos, período da publicaçáo, deficiências abordadas no texto e o sumário dos temas presentes. 
Tabela 1 - Descrição dos artigos (n=83) distribuídos em categorias.

\begin{tabular}{|c|c|c|c|c|c|c|}
\hline \multirow[t]{2}{*}{ Categorias } & \multirow[t]{2}{*}{ Descriçáo } & \multirow[t]{2}{*}{$\begin{array}{l}\text { N. } \\
83\end{array}$} & \multicolumn{3}{|c|}{\begin{tabular}{|l|c}
$\begin{array}{l}\text { Período da } \\
\text { publicaçáo }\end{array}$ & $\mathbf{a}\left(^{*}\right)$ \\
\end{tabular}} & \multirow[t]{2}{*}{ Tema } \\
\hline & & & (anos) & Tipo & $\mathrm{f}$ & \\
\hline $\begin{array}{l}\text { (1) } \\
\text { Educaçáo } \\
\text { Sexual }\end{array}$ & \begin{tabular}{|l|} 
Informaçóes sobre \\
processos de \\
educação sexual \\
para pessoas com \\
deficiência
\end{tabular} & 22 & \begin{tabular}{ll|}
1998 & $\mathrm{a}$ \\
2015 & \\
& \\
& \\
&
\end{tabular} & $\begin{array}{l}\text { DI } \\
\text { A } \\
\text { DF } \\
\text { DA/S } \\
\text { DV } \\
\text { NE }\end{array}$ & \begin{tabular}{l|}
10 \\
4 \\
3 \\
3 \\
0 \\
2
\end{tabular} & $\begin{array}{l}\text { Estudos teóricos e empíricos } \\
\text { em Educaçáo Sexual: } \\
\text { a) estratégias e açôes, } \\
\text { materiais e métodos; } \\
\text { b)necessidades } \\
\text { recomendaçóes; } \\
\text { c)análise de programas e } \\
\text { currículos }\end{array}$ \\
\hline $\begin{array}{l}\text { (2) } \\
\text { Profissio } \\
\text { nais e } \\
\text { Familiares }\end{array}$ & $\begin{array}{l}\text { Concepçóes, } \\
\text { opiniôes e } \\
\text { treinamentos para } \\
\text { professores, } \\
\text { familiares e } \\
\text { profissionais } \\
\text { envolvidos com a } \\
\text { pessoa com } \\
\text { deficiência } \\
\end{array}$ & 27 & $\begin{array}{l}1996 \text { a } \\
2016\end{array}$ & $\begin{array}{l}\text { DI } \\
\text { DF } \\
\text { DA/S } \\
\text { DV } \\
\text { A } \\
\text { NE }\end{array}$ & \begin{tabular}{|l|}
18 \\
4 \\
0 \\
0 \\
1 \\
4
\end{tabular} & $\begin{array}{l}\text { Opiniốes, concepçóes de } \\
\text { professores, pais, } \\
\text { profissionais da saúde, } \\
\text { educadores e cuidadores; } \\
\text { Cursos e treinamentos, } \\
\text { validaçóes de escalas. }\end{array}$ \\
\hline $\begin{array}{l}\text { (3) Aspectos } \\
\text { da } \\
\text { Sexualidade } \\
\text { de Pessoas } \\
\text { com } \\
\text { Deficiências }\end{array}$ & \begin{tabular}{|l} 
Descriçôes, \\
investigaçóes ou \\
discussôes sobre \\
aspectos \\
específicos \\
relacionados às \\
próprias pessoas \\
com deficiências \\
\end{tabular} & 28 & $\begin{array}{c}1999 a \\
2014\end{array}$ & $\begin{array}{l}\text { DI } \\
\text { DF } \\
\text { DA/S } \\
\text { DV } \\
\text { A } \\
\text { NE }\end{array}$ & \begin{tabular}{c|}
11 \\
7 \\
2 \\
4 \\
4 \\
0
\end{tabular} & $\begin{array}{l}\text { Desenvolvimento da } \\
\text { sexualidade, motivaçáo para } \\
\text { o serviço, barreiras e } \\
\text { dificuldades, conhecimento } \\
\text { sobre HIV/Aids, risco ao } \\
\text { abuso sexual, saúde, } \\
\text { resposta sexual, disforia de } \\
\text { gênero, fetiche, métodos de } \\
\text { estudo, informaçóes, } \\
\text { conjugalidade, experiências } \\
\text { sexuais, expectativas sobre } \\
\text { educaçấo sexual }\end{array}$ \\
\hline $\begin{array}{l}\text { (4)Questóes } \\
\text { teóricas }\end{array}$ & $\begin{array}{l}\text { Textos com } \\
\text { argumentaçôes } \\
\text { teóricas } \\
\text { relacionadas às } \\
\text { deficiências }\end{array}$ & 6 & $\begin{array}{c}1996 a \\
2013\end{array}$ & $\begin{array}{c}\text { DI } \\
\text { DF } \\
\text { DA/S } \\
\text { DV } \\
\text { A } \\
\text { NE }\end{array}$ & $\begin{array}{l}2 \\
1 \\
0 \\
0 \\
0 \\
3\end{array}$ & $\begin{array}{l}\text { Estudos queer, sexualidade e } \\
\text { deficiência física, direitos } \\
\text { sexuais, estigma e desvio, } \\
\text { sexualidade de crianças com } \\
\text { DI, abuso sexual no Pakistáo }\end{array}$ \\
\hline
\end{tabular}

$\left(^{*}\right)$ Legenda: DI (deficiência intelectual); DF (deficiência física); DV (deficiência visual), DA/S (deficiência auditiva/surdez), A (transtorno do espectro autista), NE (não especificada).

Podemos observar na Tabela 1 que o número de artigos é equilibrado nas categorias "Educação Sexual", "Profissionais e Familiares" e "Aspectos da Sexualidade das pessoas com deficiências", sendo pouco expressivos na categoria "Questôes teóricas". Entre as deficiências, a mais citada foi a deficiência intelectual (42 artigos), seguida da deficiência física (15 artigos), autismo (9 artigos), náo especificada (8 artigos), deficiência auditiva/surdez ( 5 artigos) e deficiência visual ( 4 artigos).

A discussão da sexualidade e deficiências, portanto, nessa amostra analisada, concentra-se nas áreas da deficiência intelectual e física, especialmente quando se trata de concepçóes de familiares e profissionais ou, entáo, nos aspectos da sexualida- 
de dessas pessoas. O artigo mais antigo está na categoria "Profissionais e Familiares" $(n=27)$ e o mais recente também, indicando que o intervalo maior de publicaçóes se refere à temática dos agentes que lidam com as pessoas com deficiência, sendo pais, mães, cuidadores, assistentes sociais, professores, enfermeiros, pediatras, e profissionais da saúde diversos.

O agrupamento dos 27 artigos na categoria "Profissionais e Familiares" concentrou as publicaçóes entre os anos de 1996 e 2016, e concentramos nossa análise nessa categoria, pois seria nela que encontraríamos os professores, nosso foco de investigação como profissionais da educação. A análise de conteúdo dos artigos localizados nesta categoria resultou em quatro sub categorias: "Concepçóes de professores" $(n=7)$; "Concepções de profissionais da saúde e cuidadores" $(n=6)$, "Concepções e expectativas de adultos que convivem com pessoas com deficiência e delas próprias" $(n=9)$ e "Implementação de Programas de Educação Sexual para profissionais da saúde e familiares" $(n=5)$, como estão descritas na Tabela 2.

Tabela 2 - Descrição das Sub-categorias da Categoria "Profissionais/familiares" (n=27).

\begin{tabular}{|c|c|c|}
\hline Sub-Categorias & Descrição & $\begin{array}{c}\mathrm{N}^{\circ} \text { de } \\
\text { artigos (27) }\end{array}$ \\
\hline $\begin{array}{l}\text { (2.1) Concepções de } \\
\text { professores }\end{array}$ & $\begin{array}{l}\text { O ponto de vista de } \\
\text { professores sobre } \\
\text { crianças e jovens com } \\
\text { deficiência em centros } \\
\text { educativos/escolas } \\
\text { reabilitação. }\end{array}$ & 7 \\
\hline $\begin{array}{l}\text { (2.2) Concepções de } \\
\text { Profissionais da saúde e } \\
\text { cuidadores }\end{array}$ & $\begin{array}{c}\text { O ponto de vista de } \\
\text { profissionais de saúde } \\
\text { (enfermagem, serviço } \\
\text { social, cuidadores, etc) } \\
\text { sobre crianças e jovens } \\
\text { com deficiência em } \\
\text { centros de reabilitação. }\end{array}$ & 6 \\
\hline $\begin{array}{c}\text { (2.3) Concepções e } \\
\text { Expectativas de adultos } \\
\text { que convivem com } \\
\text { pessoas com deficiência e } \\
\text { delas próprias }\end{array}$ & $\begin{array}{l}\text { O ponto de vista de um } \\
\text { conjunto de pessoas na } \\
\text { mesma investigação: } \\
\text { membros familiares, } \\
\text { profissionais diversos e as } \\
\text { próprias pessoas com } \\
\text { deficiência. }\end{array}$ & 9 \\
\hline $\begin{array}{l}\text { (2.4) Implementação de } \\
\text { Programas de Educação } \\
\text { Sexual para profissionais } \\
\text { da saúde e familiares }\end{array}$ & $\begin{array}{c}\text { Intervenções/ capacitação } \\
\text { de profissionais de saúde } \\
\text { e familiares sobre } \\
\text { educação sexual para } \\
\text { pessoas com deficiência. }\end{array}$ & 5 \\
\hline
\end{tabular}


Dentro da categoria "Profissionais e Familiares", encontramos os estudos que abordam os professores e, assim, aproximam-se do objetivo inicial do nosso estudo, que foi analisar as concepçóes de educadores diante da sexualidade de pessoas com deficiência. Será essa a categoria, cuja análise iremos aprofundar a seguir.

\section{Análise das concepções e atitudes de professores}

Para análise específica das concepçôes e atitudes de professores foram considerados os sete artigos da subcategoria (2.1) em que consta, como população alvo, os professores. Os artigos foram publicados entre os anos de 2011 e 2015, nos seguintes periódicos: Estudos de Psicologia, Psychodynamic Pratice, Sex Disability e Sex Education. Os pesquisadores eram oriundos do Brasil, Reino Unido, Estados Unidos e África do Sul.

A análise dos elementos convergentes desses artigos oferece um panorama geral sobre as concepçóes de professores que representam indícios de necessidades de formação importantes para a planificação da formação em educação sexual. Como todos os artigos se referiram à deficiência intelectual, a análise de refere às concepçóes dos professores em relaçáo a esta deficiência.

Os professores reconhecem que os seus alunos com deficiência intelectual são seres sexuais e observam as suas manifestaçóes sexuais na escola, tais como verbalizaçôes, exibicionismos, masturbação e namoro (2 artigos). Também relatam uma percepção de uma sexualidade exagerada (hiperssexualidade) (2 artigos), e uma percepçáo de que eles não entendem muito bem as informaçóes sobre sexualidade (1 artigo) e aprendem com os seus pares ou com a mídia (1 artigo).

Estes professores são favoráveis à educação sexual na escola, por reconhecerem o direito das pessoas com deficiência ao exercício da sexualidade (3 artigos). Mas, em alguns casos, são favoráveis a uma educação sexual "moralista", com finalidades de controle (1 artigo).

Em todos os casos, há aqueles professores que não consideram que seja seu papel realizar a educação sexual (1 artigo), e outros professores que acreditam que poderiam contribuir ( 3 artigos). Os professores afirmam a necessidade de terem preparo e receberem formaçáo continuada na área (3 artigos).

Além disso, os professores afirmam que carecem de materiais específicos que sejam adaptados, principalmente no caso de alunos cegos e surdos ( 5 artigos). Também referem que necessitariam de apoio e participação da família na educação sexual na escola ( 4 artigos).

Uma questáo recorrente e importante foi o reconhecimento dos professores sobre a dificuldade pessoal para falar sobre "certos assuntos", tais como masturbaçáo, abuso sexual, casamento ou as dificuldades com a própria educaçáo sexual que receberam em suas vidas e/ou crenças religiosas (6 artigos). 


\section{Programa de Capacitação em Educação Sexual para professores}

Parece evidente que os professores necessitam de formação para assumirem e atuarem como educadores sexuais. A partir dos resultados obtidos, são listados alguns apontamentos importantes que devem ser considerados na formação de professores para que tenham atitudes favoráveis diante da educação sexual de alunos com deficiência na escola:

- refletir sobre a própria história de educação sexual recebida;

- identificar as crenças e dificuldades a respeito de sexualidade;

- oferecer conhecimentos teóricos sobre educaçáo sexual na escola;

- oferecer conhecimentos teóricos sobre o desenvolvimento da sexualidade no desenvolvimento típico e no desenvolvimento de crianças e jovens com diferentes deficiências;

- pensar em estratégias de diálogo com familiares;

- buscar recursos e procedimentos que sejam acessíveis e atendam às necessidades dos alunos com deficiência;

- utilizar estratégias e recursos pedagógicos que possam ser utilizados: filmes e documentários, estudo de casos, role-playing;

- promover uma discussão sobre o assunto em grupo dos professores e da equipe escolar visando o apoio da escola e da direção em assumir a educaçáo sexual na proposta política pedagógica da instituiçáo;

- colaborar no planejamento de programas de educação sexual com objetivos pertinentes e que os professores elaborem a partir das necessidades de seus alunos com deficiência.

- supervisionar e acompanhar as açóes a partir da avaliação processual e final da implementaçáo de um programa de educaçáo sexual.

Assim, espera-se que uma formação em educação sexual e sexualidade para os professores em serviço, possa colaborar para que eles desenvolvam as atitudes positivas desejáveis para um educador sexual: preparo técnico, auto-reflexão, abertura intelectual e moral, flexibilidade, segurança, empatia, criatividade, disposiçáo para acolher as necessidades dos educandos, sinceridade, respeito, tolerância e consideraçấo com as famílias e histórias de vida de cada educando.

\section{Discussão}

Embora a localização dos artigos tenha ocorrido a partir do descritor "educação sexual”, essa educação aparece em outros contextos que não a escola: instituiçóes diversas/ reabilitação. Mesmo na categoria "Profissionais/ familiares", os professores aparecem como agentes de educaçáo sexual em número muito inferior aos outros 
profissionais e até mesmo familiares. Evidentemente as famílias e os diversos profissionais devem receber esclarecimentos e formação, mas, como é na escola que se espera que a educação sexual aconteça inserida nos conteúdos regulares, são os professores que mais necessitam dessa formação (ALBUQUERQUE; ALMEIDA, 2010; MAIA, $2010 ; 2016)$. Mas, nem na categoria de "intervençôes", o público alvo foram os professores. É preciso insistir em pesquisas de investigaçáo e de práticas que acolham as necessidades dos professores, pois na escola inclusiva se espera que os alunos com deficiência estejam a maior parte de seu tempo, e é nela que as ocorrências de comportamentos e de necessárias orientaçôes surgirấo como uma demanda ao professorado.

Em toda a amostra, a maioria dos artigos, referiu-se à deficiência intelectual e na subcategoria analisada todos os artigos foram sobre esta deficiência. Os dados sugerem que a preocupação com a sexualidade e educação sexual é maior quando se trata dessa deficiência do que em outras, como surdez, cegueira e deficiência fisica e talvez isso ocorra devido aos mitos e crenças que são mais comuns quando se trata da sexualidade das pessoas com deficiência intelectual e também pela visibilidade maior de comportamentos sexuais considerados inadequados (ANDERSON, 2000; GIAMI, 2004; HEIGHWAY; WEBSTER, 2008; KAUFMAN et al., 2003; MAIA; RIBEIRO, 2010).

Os apontamentos teóricos dos artigos complementam e reiteram, apontando a educaçáo sexual para pessoas com deficiência como um meio de diminuir vulnerabilidades (COUWENHOVEN, 2007; KAUFMAN, SILVERBERG; ODETTE, 2003; KOLLER, 2000; SANCHEZ, 2008; MAIA, 2006; MAIA; ARANHA, 2005; PEREIRA; VILAÇA, 2012). Também levantam as crenças e as dificuldades dos educadores sobre essa temática (ANDERSON, 2000; BANIM; GUY; TASKER, 1999; MAIA; RIBEIRO, 2010; SANCHES, 2008; SCHAAFSMA et. al., 2014, WILKENFELD; BALLAN, 2011) e a necessidade de formação especifica para professores (CHIRAWU et al., 2014; MAIA; ARANHA, 2005).

\section{Considerações Finais}

A deficiência intelectual parece ser a que mais preocupa professores, profissionais e familiares quando se aborda a sexualidade e a educação sexual, razão pela qual ela foi mais recorrente no conjunto dos artigos. Além disso, é preocupante perceber que o educador não é o profissional mais destacado nos artigos sobre educação sexual e pessoas com deficiências. Profissionais da saúde, cuidadores e familiares são mais frequentemente indicados como agentes a promover a educação sexual.

As categorias encontradas vão ao encontro da literatura, ressaltando algumas questôes recorrentes sobre as atitudes de professores que seriam desejáveis diante da educaçáo sexual de alunos com deficiência. Agrupar as concepçóes de professores, também é um modo de identificar o que deve ser incorporado na elaboração de propostas de formação e capacitação de professores. A proposta de formaçãa resultante deste levantamento ainda está em fase de aplicação e avaliaçáo, mas já indica resultados promissores. 


\section{Referências}

ALBUQUERQUE, P.P.; ALMEIDA, M.A. Sexualidade e deficiência intelectual: um curso de capacitaçáo de professores. Rev. Bras. Estud. Pedagog., v. 91,p. 408-423, 2010.

ANDERSON, O.H. Doing what comes naturally? - dispelling myths and fallacies about sexuality and people with developmental disabilities. 1.ed. Illinois/USA: High Tide Press, 2000.

BANIM, M.; GUY, A.; TASKER, P. Trapped in risky behaviour: empowerment, disabled people ans sexual health. Health, Risk \& Society, v.1(2), p. 209-221, 1999.

BARDIN, L. Análise de conteúdo. (Tradução de Luis Antero Reto e Augusto Pinheiro). Lisboa: Ediçôes 70, 2011.

BLACK, K. Disability and sexuality- holistic care for adolescents. Pediatric Nursing, v.17 (5), p.34-37. 2005.

COUWENHOVEN, T. Teaching children with Down Syndrome about their bodies, boundaries and sexuality - a guide for parents and professionals. 1. ed. Bethesda/USA: Woodbine House, 2007.

CHIRAWU, P.; HANASS-HANCOCK, J.; ADEREMI, T. J.; REUS, L.; \& HENKEN, A. A. Protect os emable? Teachers1 Beliefs and Practices Regarding Provisiono of Sexuality Education to leatners with Disability in KwaZulu-Natal, South Africa. Sex Disabil, v.32, p.259-277, 2014.

EAST, L. J.; ORCHARD, T.R. Somebody Else's Job: Experiences of Sex Education among Health Professionals, Parents and Adolescents with Physical Disabilities in Southwestern Ontario. Sex Disabil, v.32, 335-350, 2013.

FRANÇA-RIBEIRO, H. C. A sexualidade de pessoas com deficiência intelectual: dos mitos às reflexôes. In Secretaria Municipal de Educação de São Paulo (Org.), Referencial sobre Avaliaçáo da Aprendizagem na área da Deficiência Intelectual do Ciclo II do Ensino Fundamenta da Educaçáo de Jovens e Adultos. (pp.34-47). São Paulo: Secretaria Municipal de Educação, 2012.

GESSER, M.; NUEMBERG, A. H. Psicologia, Sexualidade e Deficiência: novas perspectivas em Direitos Humanos. Revista Ciência e Profissáo, v..34 (4), p. 850-863, 2014.

GIAMI, A. O anjo e a fera: sexualidade, deficiência mental, instituição. Tradução de Lydia Macedo. São Paulo: Casa do Psicólogo, 2004.

HATTON, S.; TECTOR, A. Sexuality and Relationship Education for young people with autistic spectrum disorder: curriculum change and staff support. British Journal of Special Education, v. 27 (2), 69-76, 2010.

HEIGHWAY, S.M., WEBSTER, S.K. S.T.A.R.S.- A Social Skills training Guide for teaching assertiveness, relationship skills and sexual awareness. ed. Texas: Future Horizons, Inc, 2008.

KAUFMAN, M., SILVERBERG, C., ODETTE, F. The ultimate guide to sex and disability - for all of us who live with disabilities, chronic pain e illness. 2a ed. Califórnia/USA: Cleis Press, 2003.

KOLLER, R. Sexuality and adolescents with Autism. Sexuality and Disability, v.18 (2), p.125-153, 2000.

LUMLEY, V, A; SCOTTI, J.V. Supporting the sexuality of adults with mental retardation: current status and future directions. Journal of positive behaviour interventions, v.3 (2), p.109-119, 2001.

MAIA, A.C.B. Sexualidade e Deficiências. 1.ed São Paulo: Ed. Unesp, 2006.

MAIA, A.C.B. Conceito amplo de Sexualidade no processo de Educação Sexual. Revista Psicopedagogia on line- Educação \& Saúde, 2010.

MAIA, A.C.B. A Educação Sexual de pessoas com deficiência intelectual. Revista ELO do Centro de Formaçáo Francisco de Holanda Guimaráes, v. 19 (1), p. 103-108, 2012.

MAIA, A.C.B. Vivencia da sexualidade a partir do relato de pessoas com deficiência intelectual. Psicol. Estud. v. 21(1): p.77-88, 2016.

MAIA, A.C.B.,; ARANHA, M.S.F. Relatos de professores sobre manifestaçôes sexuais de alunos com deficiência no contexto escolar. Interaçáo (Curitiba), 9(1), p.103-116, 2005.

MAIA, A,C.B.; REEIS-YAMAUTI, V.L.; SCHIAVO, R.A.; CAPELLINI, V.L.M.F.; VALLE, T.G.M. Teacher opinions on sexuality and Sexual Education of students with intelectual disability. Estudos de Psicologia, v. 32(3), p. 427-435, 2015.

MAIA, A.C.B., RIBEIRO, P.R.M. Desfazendo mitos para minimizar o preconceito sobre a sexualidade de pessoas com deficiências. Revista Brasileira de Educação Especial, v.16, p.169-176, 2010. 
MORALES, A. S., BATISTA, C. G. Compreensão da Sexualidade por Jovens com Diagnóstico de Deficiência Intelectual. Psicologia: Teoria e Pesquisa, v.26(2), p.235-244, 2010.

PEREIRA, T.A.R.; VILAÇA, T. Percepçôes sobre a abordagem educativa na reabilitação da sexualidade em contexto hospitalar. Revista Ibero-Americana de Estudos em Educaçáo, v. 7 (2), p.14-31, 2012.

SÁNCHEZ, P.R. Sexualidad de los niños, niñas y jóvenes con discapacidad. Revista Ecudación, v.32(1), p.157-170, 2008.

SCHAAFSMA, D.; KOK, G.; STOFFELEN, J.M.T.; VAN DOORN, P.; CURFS, L.M.G. Identifying the important factors associated with teaching sex education to people with intellectual disability: A cross-sectional survey among paid care staff. Journal of Intellectual \& Developmental Disability. v.39(2), p.157-166, 2014.

SCHWIER, K.M., HINGSBURGER, D. Sexuality - your sons and daughters with intellectual disabilities. 3a ed. Baltimore, Maryland: Paul H. Brookes Publishing Co., 2007.

VIEIRA, C. M., COELHO, M. A. Sexualidade e deficiência intelectual: concepçôes, vivências e o papel da educação. Revista Tempos e Espaços em Educaçáo, v.7(13), p.201-211, 2014.

VILAÇA, T. A multiple case study based on action-oriented sexuality education: Perspectives of Portuguese teachers. Health Education, v.117(1), p.110-126, 2017.

VILAÇA, T. InterAção no núcleo da promoção de sexualidades saudáveis: competência para a ação e uso das tecnologias de informação e comunicação na escola. Revista Linhas, v.17(34), p.28-57, 2016.

WALKER-HIRSCH, L. (2007). Sexuality Education and Intellectual Disability across the Lifespana developmental, social and education perspective. In: Walker-Hirsch, L. The Facts of Life... and more-sexuality and intimacy for people with intellectual disabilities. (p.3-28). London: Paul H. Brookes Publishing Co.

WILKENFELD, B. F.; BALLAN, M. S. Educators attitudes and beliefs towards the sexuality of individuals with developmental disabilities. Sex Disabil, v.29, 351-261, 2011.

\section{Notas}

${ }^{1}$ Este artigo baseia-se em dados parciais da pesquisa de pós-doutorado da primeira autora, sob supervisão da segunda, financiada pela FAPESP- Processo 2016/14382-0.

\section{Correspondência}

Ana Cláudia Bortolozzi Maia - Universidade Estadual Paulista Júlio de Mesquita Filho, Faculdade de Ciências de Bauru, Departamento de Psicologia. Av. Eng. Luiz Edmundo C. Coube, 14-01. Bairro: Vargem Limpa. CEP: 17033-360. Bauru, São Paulo, Brasil.

E-mail: aclaudia@fc.unesp.br - tvilaca@ie.uminho.pt

Recebido em 11 de julho de 2017

Aprovado em 11 de agosto de 2017 